\title{
PERANCANGAN MOTIF DEKORATIF PASIR BERBISIK PADA BUSANA READY TO WEAR
}

\author{
Agni Agustin \\ Program Studi S-1 Kriya, Fakultas Industri Kreatif, Tekom University, Bandung, agniagustin99@yahoo.com, \\ agniagustin@student.telkomuniversity.ac.id, 081221962426 \\ Sari Yuningsih \\ Program Studi S-1 Kriya, Fakultas Industri Kreatif, Tekom University, Bandung, sariyuningsih02@gmail.com, \\ sariyuningsih@telkomuniversity.ac.id, 081320795932
}

\begin{abstract}
Indonesia's diverse natural wealth is very interesting to browse and explore. One of the interesting phenomena is Pasir Berbisik and Edelweiss flowers on Mount Bromo, Malang, East Java. Pasir Berbisik comes from the phenomenon when the wind blows and grains of sand fly and sounds like a whisper in everyone's ear passing by, this phenomenon has an interesting and unique visualization to be used as a decorative element in clothing. In this study, these uniqueness will be explored with various textile decorative techniques to produce ready-to-wear designs, inspired by Pasir Berbisik and Edelweiss flowers. The result of this study is a collection of ready-to-wear clothing inspired by Pasir Berbisik and Edelweiss flowers with Tie dye and embroidery techniques. With this collection, it is hoped that it can provide a new alternative in the development of ready-to-wear clothing for academics or fashion practitioners.
\end{abstract}

Keywords : ready-to-wear, pasir berbisik, Edelweiss, tie dye, classic

\section{ABSTRAK}

Kekayaan alam Indonesia yang beragam sangat menarik untuk ditelusuri dan diekplorasi. Salah satu fenomena yang menarik, yaitu pasir berbisik dan bunga Edelweis di Gunung Bromo, Malang, Jawa timur. Pasir berbisik berasal dari fenomena ketika angin bertiup lalu butiran-butiran pasir beterbangan dan terdengar seperti bisikan di telinga setiap orang yang melewatinya. Fenomena tersebut memiliki visualisiasi yang menarik dan unik untuk dijadikan salah satu elemen dekoratif pada busana. Pada kajian ini, keunikan tersebut akan diekplorasi dengan berbagai teknik dekoratif tekstil untuk menghasilkan rancangan busana siap pakai, dengan inspirasi pasir berbisik dan bunga Edelweis. Hasil dari kajian ini berupa koleksi busana siap pakai dengan inspirasi pasir berbisik dan bunga Edelweis dengan teknik tie dye dan bordir. Dengan koleksi tersebut diharapkan dapat memberikan alternatif baru dalam pengembangan busana siap pakai bagi akademisi atau praktisi bidang fesyen.

Kata Kunci: busana siap pakai, pasir berbisik, Edelweis, tie dye , klasik

\section{PENDAHULUAN}

Ready-to-wear atau prêt-à-porter adalah istilah untuk pakaian buatan pabrik, dijual dalam kondisi jadi, dalam ukuran standar, berbeda dari pakaian yang dibuat untuk mengukur atau dipesan lebih dahulu yang disesuaikan dengan kerangka orang tertentu. Ready-to-wear memiliki konotasi yang agak 
berbeda di bidang mode dan pakaian klasik. Dalam industri fashion, desainer memproduksi pakaian siap pakai yang dimaksudkan untuk dipakai tanpa perubahan signifikan, karena pakaian yang dibuat dengan ukuran standar akan lebih fleksibel untuk semua kalangan. Pembuatan busana ini menggunakan pola standar, peralatan pabrik, dan teknik konstruksi yang lebih cepat untuk menjaga biaya tetap rendah, dibandingkan dengan versi customdijahit dari barang yang sama. Beberapa rumah mode dan perancang mode memproduksi pakaian jadi yang siap pakai yang diproduksi secara massal dan industri, sementara yang lain menawarkan pakaian yang, meskipun tidak unik, diproduksi dalam jumlah terbatas.

Pada penelitian ini, busana akan dibuat berbeda dengan konsep motif yang menggunakan lokal konten dari Bromo. Hal ini dimaksudkan agar memajukan industri fashion Indonesia, dan mengenalkan kekayaan Indonesia melalui Industri ini. Bromo merupakan gunung yang menjadi bagian dari Taman Nasional Bromo Tengger Semeru memiliki tinggi mencapai 2.359 meter, luasnya mencapai 5.300 hektar yang dilengkapi dengan lembah dan ngarai yang dikelilingi hamparan pasir. Bromo juga merupakan salah satu gunung berapi yang masih aktif di Jawa Timur. Gunung Bromo memiliki ikon-ikon menarik dan menjadi ciri khas kawasan Bromo itu sendiri, yaitu pasir berbisik dan bunga Edelweis.

Saat mendaki Gunung Bromo, menjadi hal biasa bagi beberapa pendaki membawa bunga Edelweis. Edelweis diyakini sebagai bunga abadi karena mempunyai hormon yang dapat mencegah kerontokan kelopak bunga. Sebab itulah para sebagian pendaki membawa bunga ini karena mempunyai sifat keabadian dan tidak akan pernah layu. Mengenai pasir berbisik, tercipta dari hasil erupsi gunung lautan pasir yang ada di sekitar Gunung Bromo. Julukan pasir berbisik berasal dari fenomena ketika angin bertiup lalu butiran-butiran pasir beterbangan dan terdengar seperti bisikan di telinga setiap orang yang melewatinya.

Pada penelilitian ini, objek lokal konten yang akan diambil untuk perancangan motif ialah alur pasir berbisik dan bunga Edelweis yang mewakili Gunung Bromo itu sendiri. Berdasarkan eksperimen eksplorasi yang telah dilakukan, hasil motif pasir berbisik yang paling optimal menggunakan teknik pewarnaan tie dye atau celup rintang, karena teknik ini mempunyai kelebihan, yaitu memiliki proses pembuatan yang sederhana dengan cepat dan mudah menghasilkan motif pada kain, motif yang dihasilkan memiliki nilai artistik yang cukup tinggi, dan berpotensi sebagai metode pada karya seni kriya (Widodo, 2013). Sedangkan hasil motif bunga Edelweis yang paling optimal menggunakan teknik bordir mesin.

\section{METODE}

Metode pengumpulan data yang digunakan adalah deskriptif kualitatif dan data Primer. Data kualitatif diperoleh dari studi literatur terkait pengertian ready to wear dan Bromo kekayaan Indonesia. Data primer diperoleh dari penelitian mata kuliah Busana Dasar, semester 4, di Fakultas Industri Kreatif, Telkom University. Analisis data dilakukan dengan metode $5 \mathrm{~W} 1 \mathrm{H}$ yang mencakup What, Who, When, Where, Why dan How. Analisis bertujuan untuk melakukan investigasi dan penelitian terhadap masalah yang terjadi dalam proses produksi. Konsep ataupun metode 5 W1H ini tentunya tidak hanya dapat digunakan dalam proses produksi (Atmaja dkk., 2018).

1. What?

Permasalahan yang diangkat pada perancangan ini adalah tentang merancang 
busana ready-to-wear yang menggunakan tren classic chic yang mendefinisikan busana kasual yang terkesan santai dan nyaman digunakan dan memberi sentuhan klasik namun tetap stylish. Potongan baju yang dipilih terkesan loose, dengan potongan yang tidak pas dengan badan. Hal ini dimaksudkan agar pemakai bebas bergerak nyaman dan fleksibel. Penciptaan ini menggunakan motif pasir berbisik dan bunga Edelweis sebagai lokal konten dari Bromo, dan memakai teknik tie dye dan bordir untuk pewujudan motifnya.

\section{Who?}

Berkaitan dengan sasaran atau target market dari perancangan busana yang dilakukan, yakni ditujukan kepada perempuan berstatus sosial menengah ke atas memiliki rentang usia 18-25 tahun dengan mobilitas tinggi dan tinggal di kota Mertopolitan, memiliki karakter fashionable, percaya diri, dan menyukai hal klasik, serta menyukai aktivitas luar, seperti traveling dan photography.

\section{Where?}

Berkaitan dengan hasil perancangan pada penelitian ini, bertujuan agar target market dapat melihat dan menjangkau. Hasil perancangan ditujukan pada perempuan dewasa muda bertempat tinggal di kota metropolitan, seperti: Jakarta dan Bandung. Berdasaran observasi lapangan, kota-kota tersebut memliki selera berpakaian yang cukup tinggi atau fashionable. Selain itu, kedua kota tersebut cukup sering menjadi lokasi acara kesenian dan kebudayaan.

\section{When?}

Waktu yang tepat untuk pemasaran produk yang dirancang. Berdasarkan data kualitatif yang didapat dari studi literatur dan hasil observasi di lapangan pada produsen busana terkemuka, situs-situs online fashion dunia, serta terkait tren fashion 2019 dalam Cosmopolitan, waktu yang tepat dengan produk yang dirancang ini adalah untuk spring/summer
2019.

\section{Why?}

Alasan mengapa produk ini perlu untuk dirancang adalah ingin memajukan industri Fashion Indonesia dengan mengembangkan lokal konten dengan ketertarikan penulis mengenai ikon-ikon Bromo yang dapat diolah menjadi motif dengan teknik-teknik mengolah surface kain, antara lain tie dye dan border, disesuaikan dengan busana ready to wear yang mempunyai potongan loose, serta mempunyai kesan klasik namun tetap stylish.

\section{How?}

Berkaitan dengan bagaimana membuat perancangan motif pasir berbisik, perancangan karya ini menggunakan teknik tie dye. Berdasarkan latar belakang pada perancangan ini, rumusan masalah yang didapat berkaitan dengan cara pengaplikasian teknik tie dye untuk mewujudkan motif pasir berbisik dan cara menonjolkan lokal konten pada busana readyto-wear yang dirancang.

Adapun pendekatan beberapa teori yang digunakan sebagai studi literatur pada perancangan ini sebagai berikut:

1. Teori busana ready-to-wear, Secara umum busana ready-to-wear dapat langsung dipakai dengan mudah tanpa harus melakukan pengukuran badan yang spesifik karena busana ini diproduksi menggunakan standard clothing size. Namun, ada beberapa pengertian ready-to-wear, sebagai berikut :

a. Ready-to-wear secara keseluruhan diproduksi berdasarkan ukuran standar yang telah ditetapkan, yaitu XS, S, M, L, XL, dan terdapat ukuran tambahan, yaitu XXL atau XXXL.

b. Ada beberapa rumah mode haute couture yang memasarkan busana ready-to-wear.

c. Perkembangan busana ready-to-wear saat ini tidak identik dengan pakaian rumah, sebab material yang digunakan untuk ready-to-wear saat ini tidak sedikit yang menggunakan bahan berkualitas dengan 
kisaran yang cukup mahal layaknya haute couture.

d. Dengan target produksi yang begitu besar, dan melibatkan mesin-mesin produksi masal, tentunya detail busana ready-towear tidak serumit haute couture.

2. Teori teknik-teknik Tie dye, terkait teknik yang digunakan untuk membentuk motif pasir berbisik, dan akan melakukan eksplorasi menggunakan teknik-teknik dasar, sebagai berikut :

\section{a. Teknik Ikat (Tie)}

Jumput area kain yang akan diaplikasikan motif. Ikat area tersebut dengan karet atau tali plastik (raffia) atau benang sintetis (Widodo, 2013). Lakukan kembali dua hingga tiga ikatan di bawahnya atau sesuai rancangan yang diinginkan (Widodo, 2013), kemudian lanjutkan dengan pewarnaan, setelah pewarnaan selasai ikatan dibuka (Widodo, 2013). Dari teknik ini dapat menghasilkan berbagai macam motif seperti :

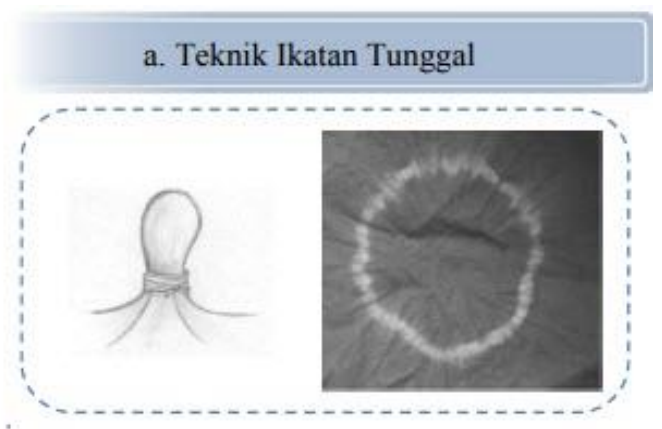

Gambar 1. Teknik Ikat Tunggal

(Sumber: mikirbae.com, 2020)

b. Teknik Ikatan Silang

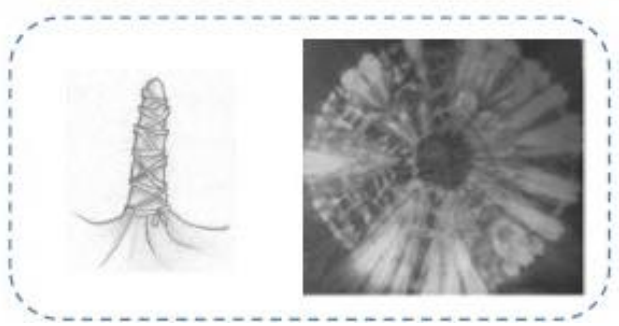

Gambar 2. Teknik Ikat Silang

(Sumber: mikirbae.com, 2020)

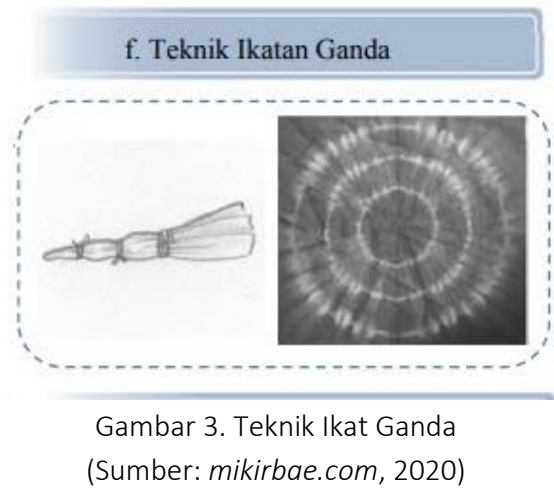

b. Teknik Fold atau Simpul

Pertama, kain dilipat atau digulung, kemudian diikat pada beberapa bagian menggunakan karet atau tali plastik (raffia) atau benang sintetis, kemudian lanjutkan dengan pewarnaan, setelah pewarnaan selasai ikatan dibuka (Widodo, 2013). Pada teknik ini dapat menghasilkan motif garis vertikal sesuai dengan cara pengikatan, dapat menghasilkan garis lurus maupun berkelok (Widodo, 2013).

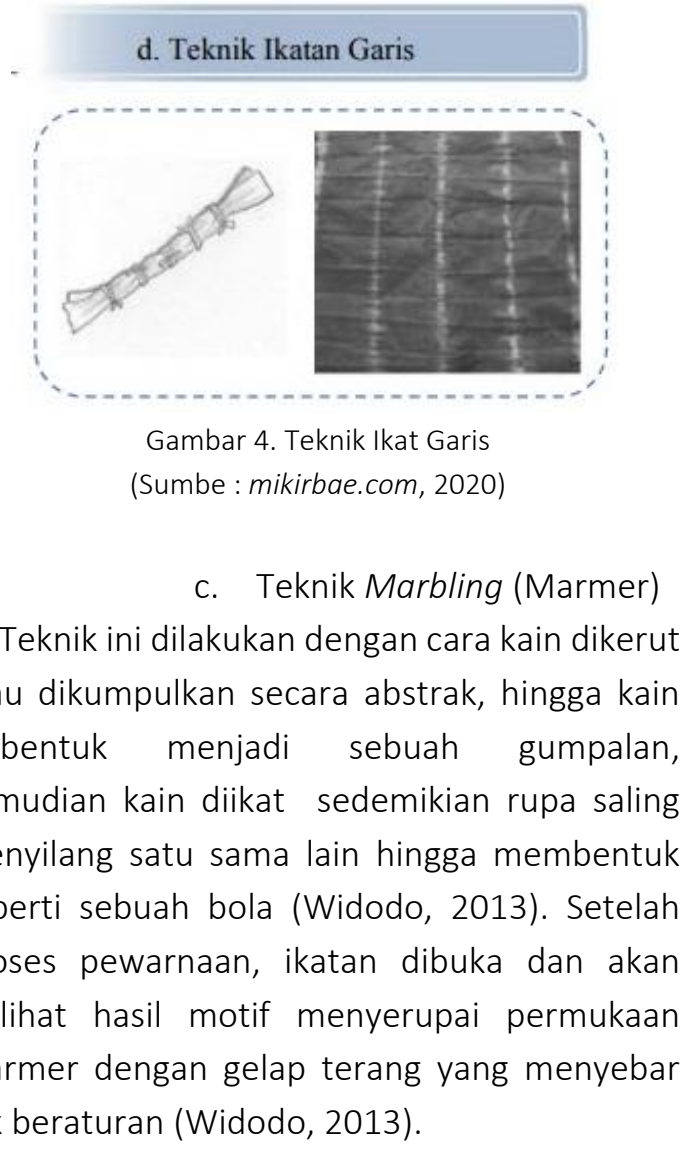




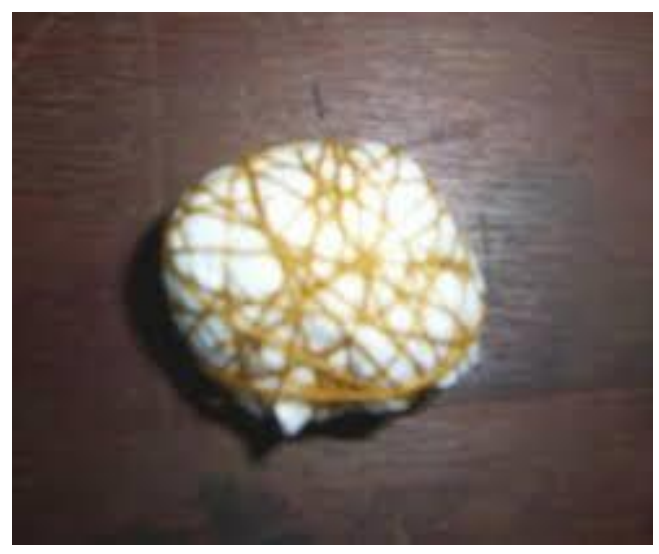

Gambar 5. Teknik Ikat Marble (Sumber: Widodo, 2013)

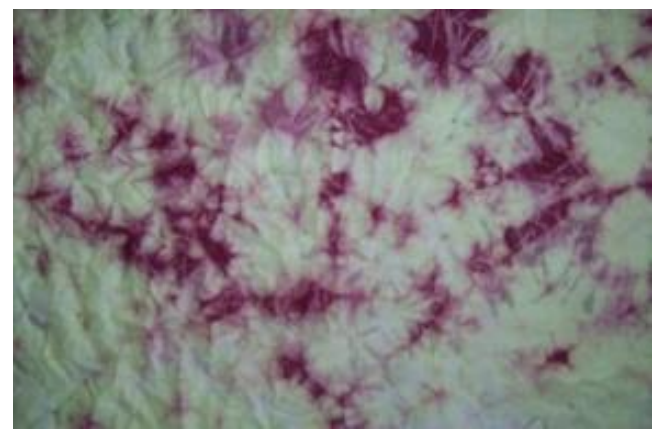

Gambar 6. Hasil Ikat Marble (Sumber: Widodo, 2013)

d. Teknik Stitch (Jahit)

Pertama, membuat garis sebagai jalur jahit yang akan menjadi motif, kemudian proses jahit jelujur menggunakan tangan (Widodo, 2013). Jarak antarjahitan disesuaikan dengan ukuran motif yang diinginkan, umumnya berjarak 0,5 $1 \mathrm{~cm}$ antar titik jahitan (Widodo, 2013). Setiap $10 \mathrm{~cm}$ jahitan, kain dikerutkan bertahap yang bertujuan menjaga kerapatan dan ketahanan pada proses pewarnaan, namun harus diperhatikan benang harus dijaga agar jangan sampai terputus (Widodo, 2013). Setelah selesai, benang ditarik dan disimpul kuat-kuat agar tidak terkena perembesan warna. Lakukan proses pewarnaan dan benang dilepas secara perlahan. Hasil dari teknik ini berupa garis putus-putus dengan motif yang sudah dirancang sebelumnya.

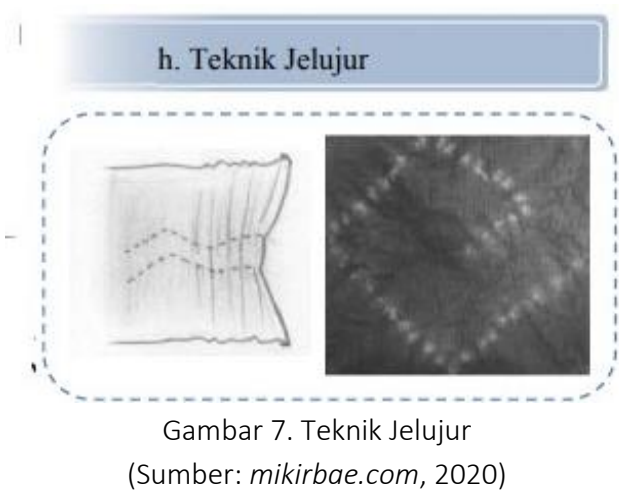

e. Teknik Roll atau Gulung

Teknik roll gulung mirip dengan teknik fold atau simpul, hanya terdapat perbedaannya kain digulung pada sebuah pipa atau pralon. Salah satu ujung kain diikat menggunakan tali plastik (raffia), sebelumnya kain harus dibasahi, digulung, dan dikerut secara bertahap menuju ujung yang terikat (Widodo, 2013). Setelah kain dikerutkan, seluruh bagian ujung kain diikat agar tetap kencang dan tidak bergeser pada waktu proses pewarnaan (Widodo, 2013). Selanjutnya proses pewarnaan, lalu ikatan dibuka, dan lepaskan kain dari pipa. Teknik ini dapat menghasilkan motif seperti aliran air di tepian sungai (Widodo, 2013).

\section{f. Teknik Pleat (Lipat)}

Teknik ini dilakukan dengan cara melipat kain sesuai garis motif yang diinginkan. Teknik ini biasanya dibantu dengan bantuan setrika agar motif lebih presisi. Selain setrika, agar motif lebih terbentuk biasanya kain dihempit duplex yang dikunci oleh clamp $g$. Selanjutnya kain dicelupkan pada pewarna namun hanya pada ketiga bagian sudutnya saja (kain tidak dicelupkan semuanya ke dalam warna). Tahap selanjutnya, lipatan dibuka dan menghasilkan motif berupa pola yang berulang seperti motif ceplok pada batik (Widodo, 2013). 


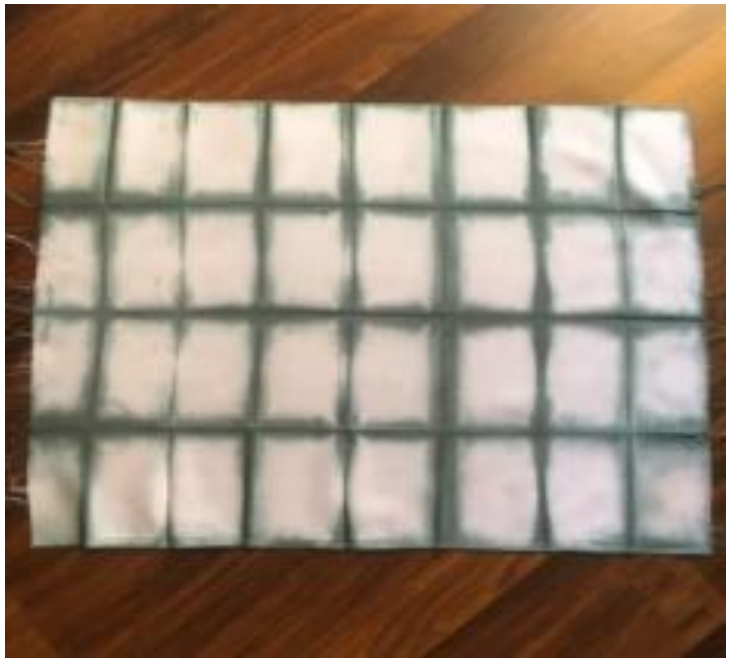

Gambar 8. Hasil Teknik Lipat/Shibori (Sumber: Agustin, 2019)

3. Teori teknik bordir, terkait teknik yang digunakan untuk membentuk motif bunga Edelweis, menggunakan teknik bordir. Bordir atau sulaman merupakan teknik surface kain yang dibuat dengan alat dan bahan, seperti jarum jahit dan benang. Selain benang, hiasan untuk sulaman atau bordir dapat menggunakan bahan-bahan seperti potongan logam, mutiara, manikmanik, bulu burung, dan payet. Jenis-jenis bordir antara lain :

a. Bordir komputer, proses bordir dengan program sistem komputerisasi

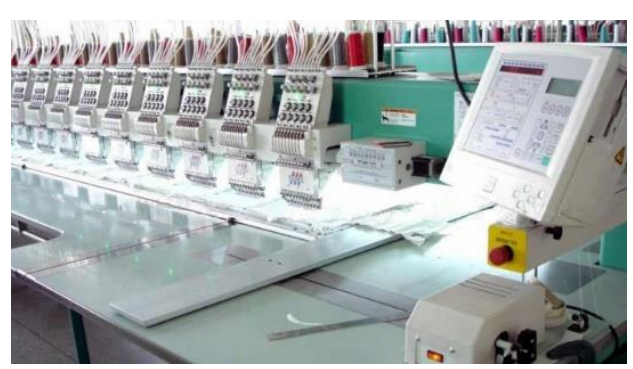

Gambar 9. Hasil Teknik Lipat/Shibori.

(Sumber: tokopedia.com, , 2020)

b. Bordir aplikasi, proses bordir dengan penambahan kain pada bordiran yang kemudian direkatkan dengan bordir jumping di sisi kain tersebut. Biasanya menggunakan kain felt, parasit wp, oscar, kulit, laken.

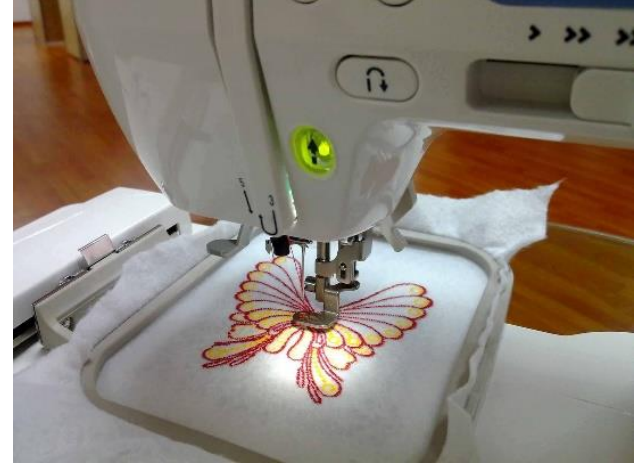

Gambar 10. Bordir Aplikasi

(Sumber: galerikonveksi51.com, 2020)

c. Bordir tangan, proses bordir sulam dengan menggunakan tangan. Pada sulam tangan, jenis tusuk yang dipakai bervariasi.

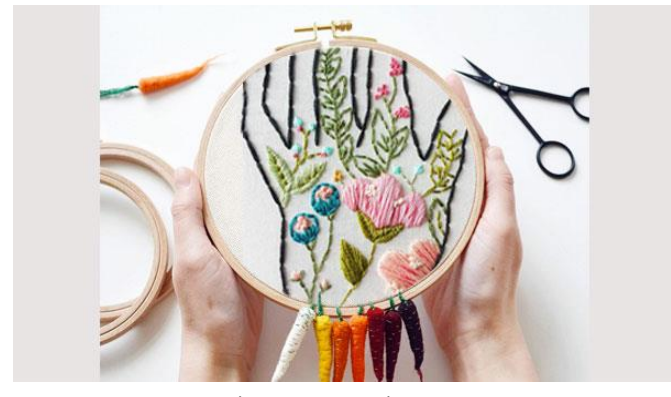

Gambar 11. Bordir Tangan

(Sumber: galerikonveksi51.com, 2020)

d. Bordir Towel/Handuk

Border yang menghasilkan tekstur seperti handuk dan banyak digunakan pada jaket vastity.

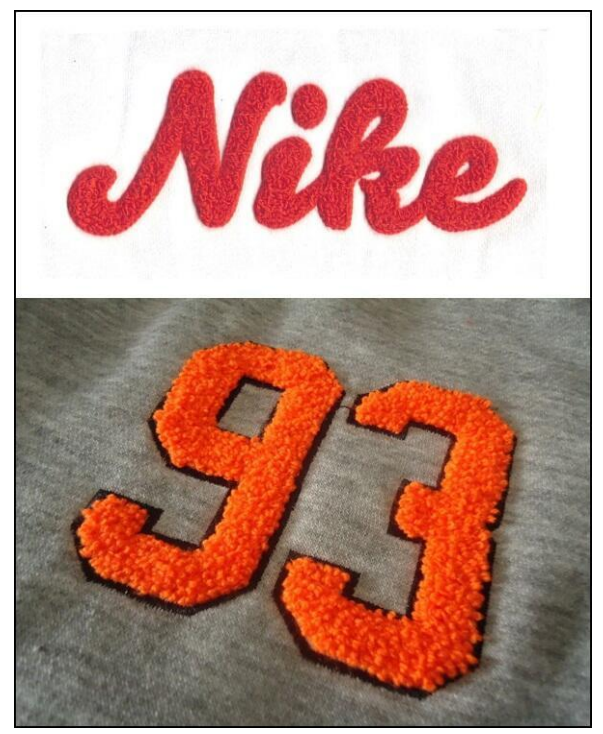

Gambar 12. Bordir Handuk

(Sumber: twitter.com, 2020) 
e. Border Timbul

Bordir yang akan menghasilkan dimensi pada kain/permukaan.

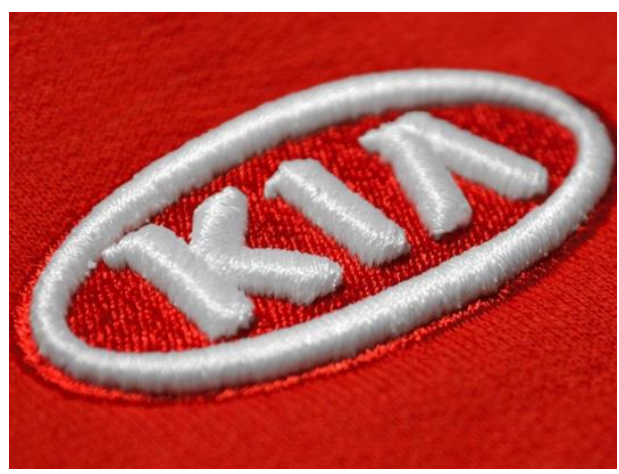

Gambar 13. Bordir Timbul

(Sumber: ordertopibandung.com, 2020)

f. Bordir mesin, proses pembuatannya dilakukan oleh mesin, bisa menggunakan mesin jahit, mesin border, atau mesin bordir komputer. Pada sulam mesin, jenis tusuk yang digunakan kurang bervariasi.

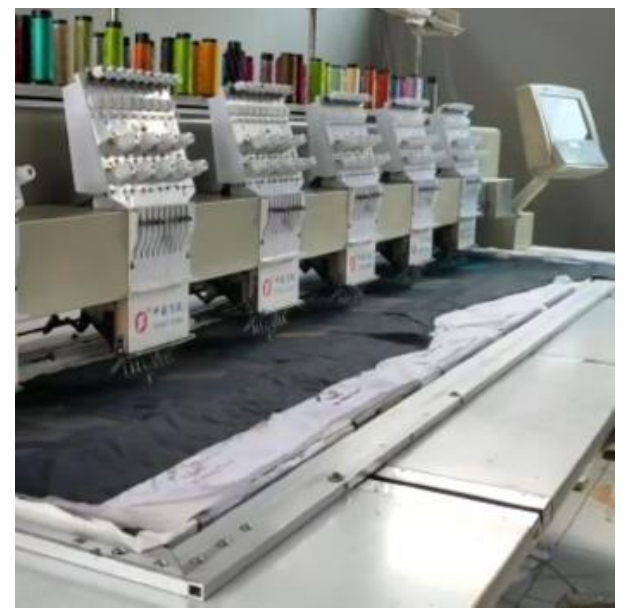

Gambar 14. Bordir Mesin

(Sumber: mblanja.com, 2020)

\section{HASIL DAN PEMBAHASAN}

Berdasarkan pemaparan mengenai lokal konten Bromo sebelumnya, dapat ditampilkan konsep dan inspirasi perancangan ini melalui image board pada gambar 15. diambil dari portofolio Loose Eternal (final project portfolio) 2019.

Loose Eternal merupakan kata-kata serapan yang mewakili dari filosofi local dan tren modern. Loose yang memiliki arti bebas, mewakili dari tren modern pada siluet baju yang didesain, memiliki potongan yang tidak pas dengan badan, dimaksudkan agar pemakai bebas bergerak, nyaman, dan fleksibel. Eternal arti yang memiliki abadi, kekal, lestari, mewakili dari filosofi local. Edelweis yang mempunyai julukan bunga abadi ini membuat penulis tertarik mengangkatnya ke dalam judul, sehingga bila digabungkan Loose Eternal bermakna "kebebasan yang abadi". Loose Eternal adalah rancangan/desain yang mempunyai kesan bebas bergerak, kasual, dan bisa dipakai dalam berbagai situasi.

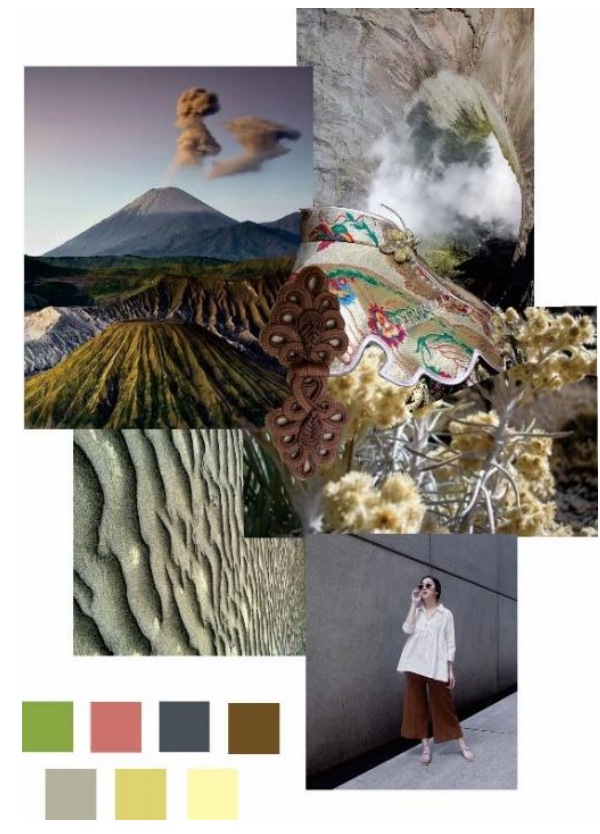

Gambar 15. Image Board Loose Eternal

a. Lokal Konten

Edelweiss dan pasir berbisik merupakan ikon dari Gunung Bromo, Malang, Jawa Timur. Saat mendaki Gunung Bromo dan membawa bunga Edelweiss sudah menjadi hal biasa bagi beberapa pendaki. Edelweis diyakini sebagai bunga abadi karena mempunyai hormon yang bisa mencegah kerontokan kelopak bunga. Sebab itulah para sebagian pendaki membawa bunga ini karena bunga edelweis mempunyai keabadian dan tidak akan pernah layu. Sedangkan mengenai pasir 
berbisik, tercipta dari hasil erupsi gunung lautan pasir yang ada di sekitar Gunung Bromo. Julukan pasir berbisik, berasal dari fenomena ketika angin bertiup lalu butiran-butiran pasir beterbangan dan terdengar seperti bisikan di telinga setiap orang yang melewatinya.

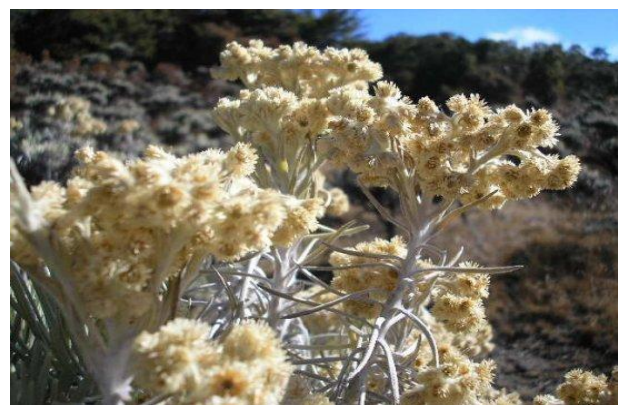

Gambar 16. Image Board Loose Eternal

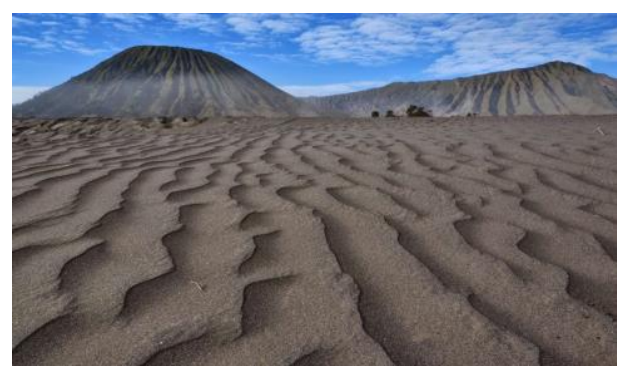

Gambar 17. Pasir Berbisik

\section{b. Trend}

Classic chic - Chic berasal dari kata Prancis 'chique' yang berarti keterampilan dan keanggunan, dgunakan untuk menggambarkan seorang wanita yang cerdas, berkelas, dan stylish. Kesan yang menggambarkan seseorang terlihat modis dan terlihat stylish, tetapi tidak berarti mereka harus terlihat memakai tren terbaru dan brand tertentu. Sedangkan kasual didefinisikan sebagai pakaian santai yang nyaman dan dapat dipakai sehari hari. Casual dan chic jika digabungkan menjadi pakaian yang santai dan nyaman, namun tetap memberikan sentuhan berkelas dan tetap stylish.

\section{c. Target Market}

Seorang wanita berstatus sosial menengah ke atas memiliki rentang usia 18-25 tahun, memiliki pekerjaan sebagai mahasiswi atau selebgram memiliki mobilitas tinggi dan bertempat tinggal di kota metropolitan, seperti Jakarta atau Bandung, memiliki karakter yang fashionable, percaya diri, dan menyukai hal klasik, serta menyukai aktivitas luar, seperti traveling dan photography.

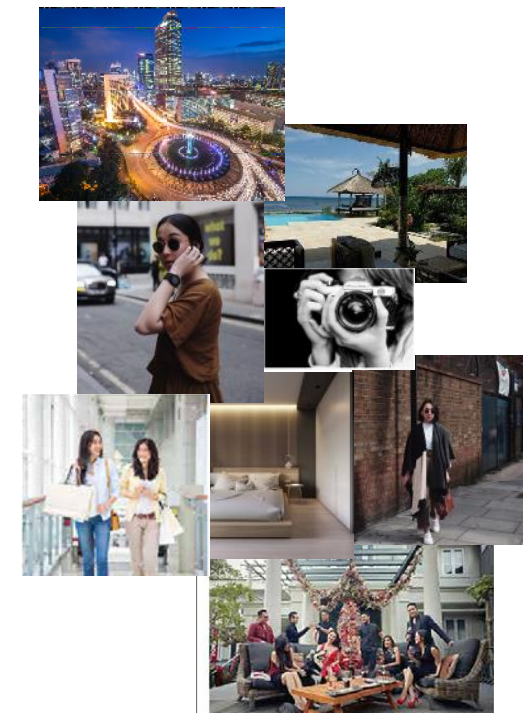

Gambar 18. Client Board

\section{d. Scamper Design}

Terdiri atas tiga items, yaitu Bustier, cullote, dan outer.

Combine, kombinasi antara batwing outer yang memiliki pattern bunga Edelweis dengan inner crop berwarna kuning yang menyesuaikan dari warna bunga Edelweis, dan celana kulot berwarna cream.

Adapt, motif yang terdapat pada bagian belakang mengadaptasi dari kumpulan bunga Edelweis, lihat gambar 19.

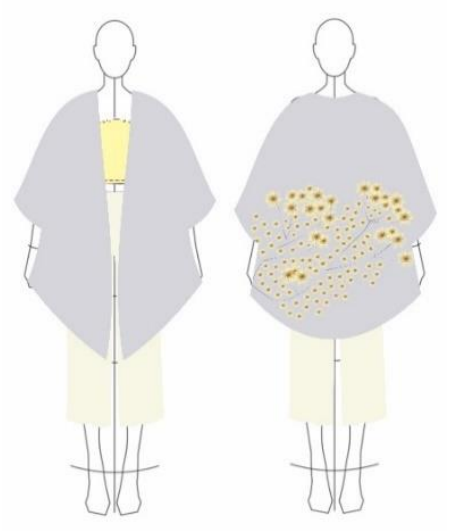

Gambar 19. Desain Koleksi Loose Eternal 


\section{e. Eksplorasi}

Motif pasir berbisik dan bunga Edelweis distilasi terlebih dahulu dalam bentuk digital, lalu diwujudkan dengan bentuk eksplorasi dengan teknik tie dye, flocking, border, lihat gambar 20, 21, dan 22.

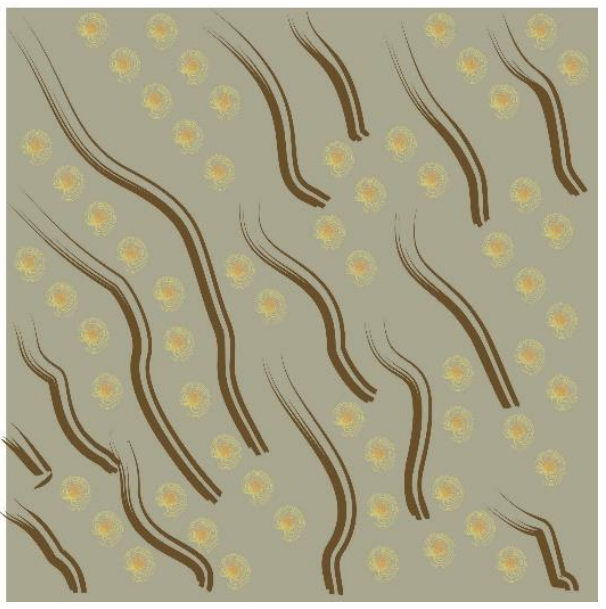

Gambar 20. Motif Stilasi Pasir Berbisik

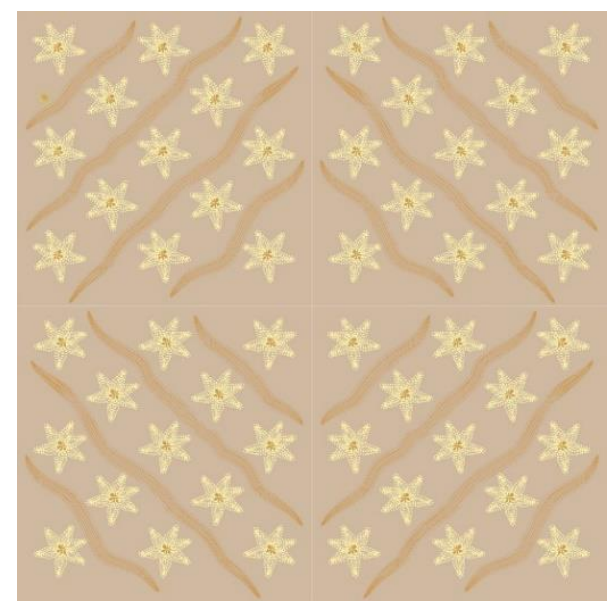

Gambar 21. Motif Stilasi Pasir Berbisik

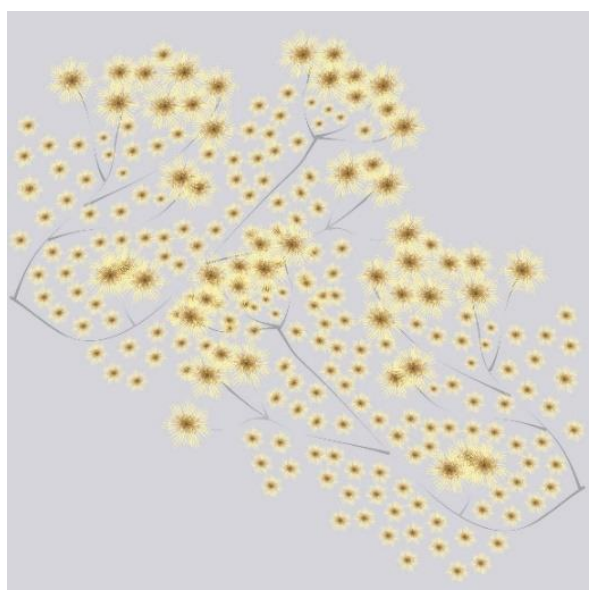

Gambar 22. Motif Stilasi Pasir Berbisik
Pada outer, penulis menggunakan kain Rayon Viscose berwarna abu-abu dengan menyesuaikan color scheme pada image board, dan motif pasir berbisik menggunakan teknik lipat tie dye dengan menggunakan pewarna wantex coklat tua dan kuning drill 1:1, lihat gambar 23.

Pada Bustier, penulis menggunakan kain Polyester Crepe berwarna kuning, lalu untuk menyesuaikan dengan warna pasir berbisik pada outer, surface pada bustier menggunakan teknik marbling tie dye, dengan menggunakan pewarna yang sama, dan menggunakan teknik flocking agar mewujudkan tekstur pasir berbisik pada bustier, lihat gambar 24 dan 25.

Bunga Edelweis pada outer, diwujudkan dengan menggunakan teknik border mesin, lihat gambar 26.

Untuk surface pada kulot, penulis menggunakan teknik jahit mesin untuk membentuk ruffle agar merespons alur pasir berbisik dengan menggunakan kain polyester dan Tulle berwarna abu-abu, lihat gambar 27.

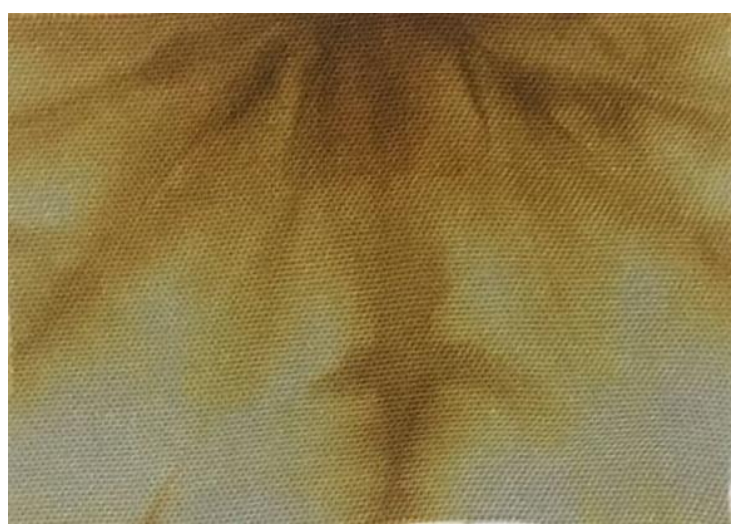

Gambar 23. Hasil Teknik Lipat Tie Dye

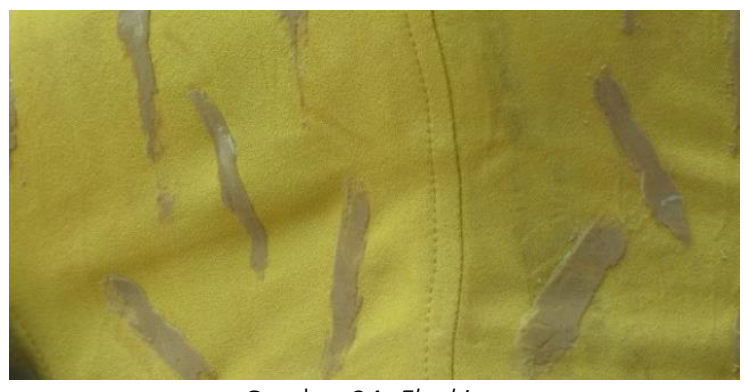

Gambar 24. Flocking 


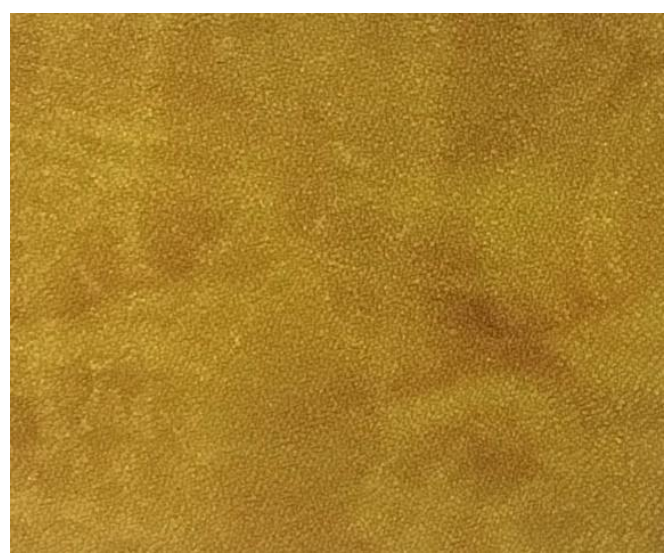

Gambar 25. Hasil Teknik Marbling Tie Dye

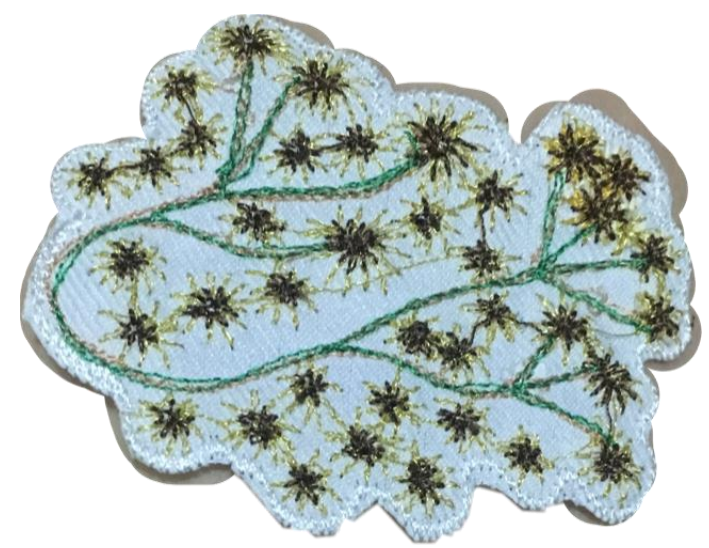

Gambar 26. Border

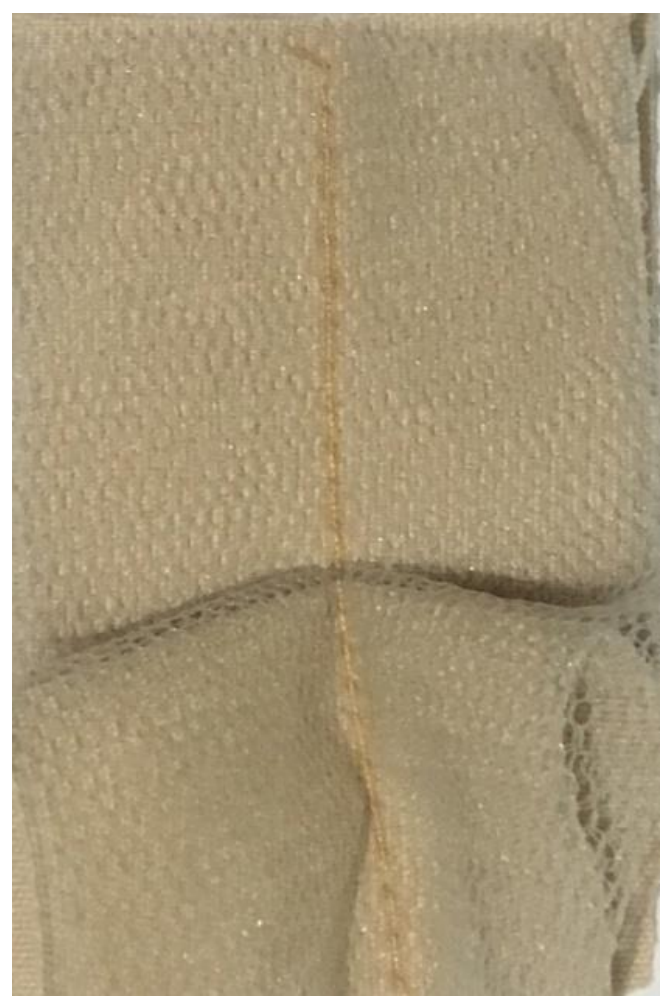

Gambar 27. Hasil Ruffle dengan Teknik Jahit Mesin

\section{f.Photoshoot Desain}

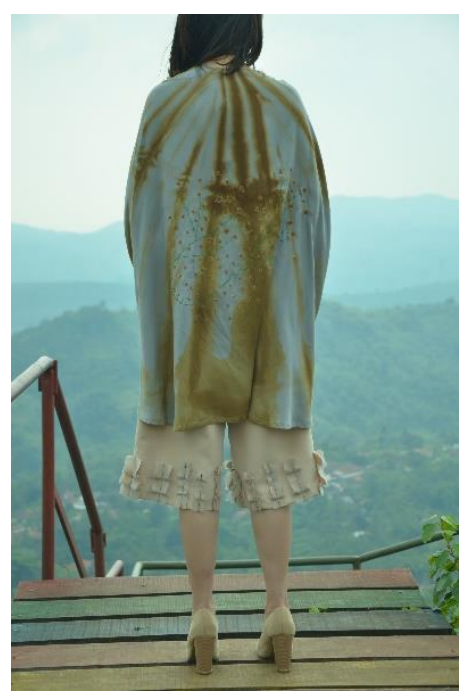

Gambar 28. Photoshoot Desain Tampak Belakang

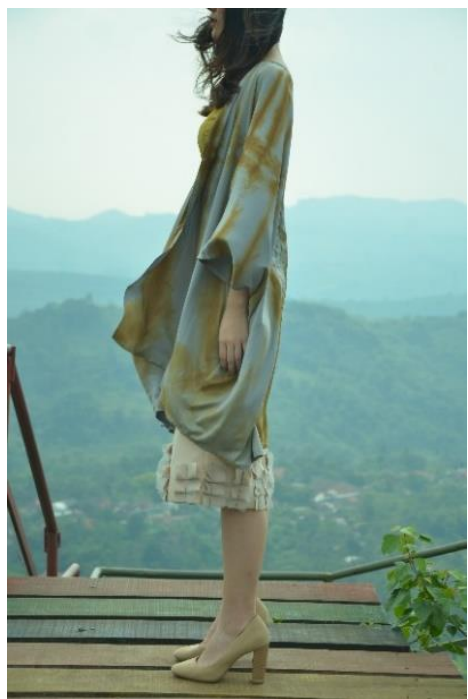

Gambar 29. Photoshoot Desain Tampak Samping

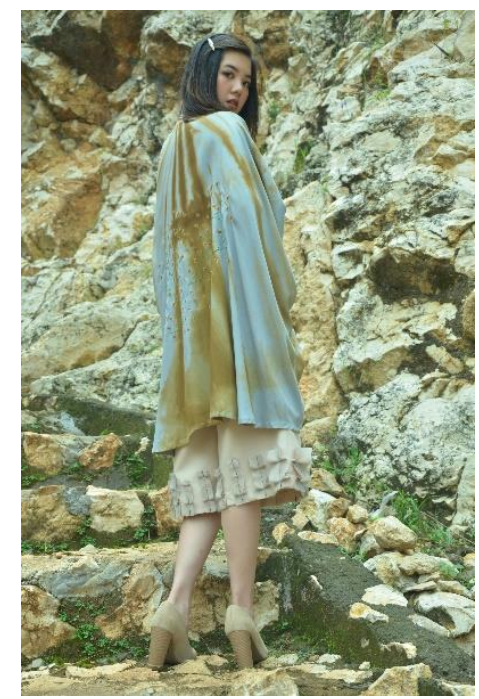

Gambar 30. Photoshoot Desain Campaign 


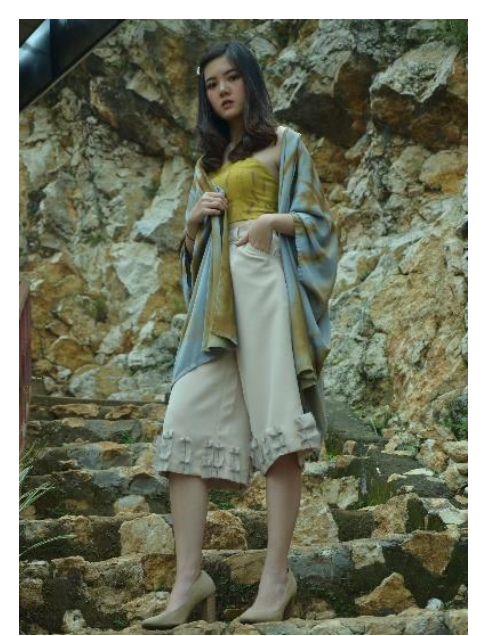

Gambar 31. Photoshoot Desain Campaign
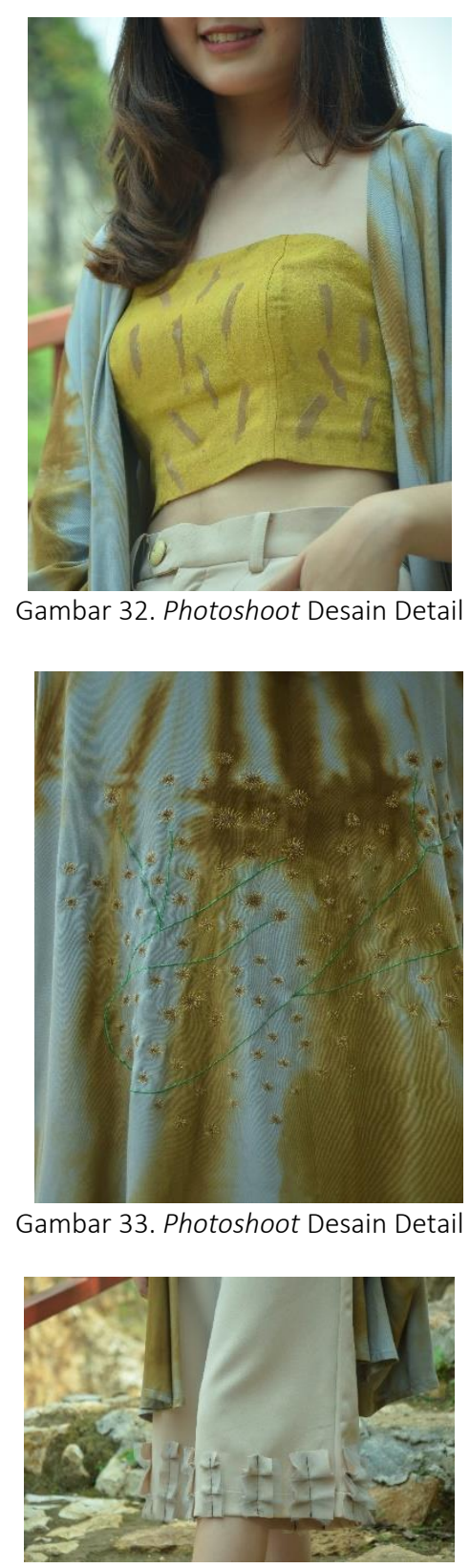

Gambar 34. Photoshoot Desain Detail

\section{PENUTUP}

Perancangan busana ready-to-wear ini menggunakan lokal konten Gunung Bromo, Malang, Jawa Timur, sebagai inspirasi utama untuk perancangan motif surface kain busana, dengan lokal konten yang diambil dari Bromo berupa fenomena pasir berbisik dan bunga Edelweis, karena kedua objek tersebut merupakan ikon yang sangat khas dari Gunung Bromo. Koleksi busana ini dinamakan Loose Eternal yang mendefinisikan rancangan/desain yang mempunyai kesan bebas bergerak, kasual, dan bisa dipakai dalam berbagai situasi.

Busana ini mempresentasikan busana ready-to-wear yang memiliki value kekayaan Indonesia, karena terinspirasi dari Gunung Bromo, khususnya pada fenomena pasir berbisik, dan bunga Edelweis, dikombinasikan dengan gaya Classic Chic, yang membuat busana menjadi pakaian yang santai dan nyaman namun tetap memberikan sentuhan berkelas dan tetap stylish.

Pembuatan busana ready-to-wear ini mengggunakan teknik-teknik surface sederhana untuk menghasilkan motif Pasir Berbisik dan bunga Edelweis, yaitu menggunakan Teknik lipat tie dye, Flocking, dan border.

Koleksi Loose Eternal Ready-to-wear ini ditujukan untuk seorang wanita berstatus sosial menengah ke atas memiliki rentang usia 18-25 tahun, memiliki pekerjaan sebagai mahasiswi atau selebgram dengan mobilitas tinggi dan tinggal di kota metropolitan, seperti Jakarta atau Bandung, memiliki karakter yang fashionable, percaya diri, dan menyukai hal klasik, serta menyukai aktivitas luar, seperti traveling dan photography. Adapun kendala dalam proses pembuatan koleksi ini, yaitu pencelupan tie dye dengan panjang kain yang cukup panjang, sehingga proses pewarnaan tidak dapat direbus melainkan hanya didiamkan selama beberapa menit. Selain itu, proses pembuatan eksplorasi pada kulot dengan teknik 
jahit dan lipat agar menyerupai ruffle, dengan menggunakan kain polyester dan tulle, dengan kesulitan meratakan panjang ruffle satu sama lain, dan proses pelipatan yang cukup sulit agar lipatan presisi satu sama lain.

\section{Ucapan Terima Kasih}

Ucapan terima kasih disampaikan kepada Ibu Sari Yuningsih, S.Pd., M. Ds selaku dosen pembimbing Kerja Profesi dan penulis ke dua.

\section{DAFTAR PUSTAKA}

Atmaja L.T, E. Supriadi, S. Utaminingsih. 2018. Analisis Efektivitas Mesin Pressing ph-1400 Dengan Metode Overall Equipment Effectiveness (oee) di Pt. Surya Siam Keramik. Teknologi 1(1).

Atmatama, A.Y. 2013. Bukit Kekayaan Indonesia Ada di Bromo. Retrieved April 20, 2013, from

https://travel.detik.com/dtravelers_storie s/u-2218224/bukti-kekayaan-indonesiaada-di-gunung-bromo

A'la, S.R. 2017. Menengok Gunung Bromo, Pesona Indonesia. Retrieved Agustus 11, 2017, from https://www.goodnewsfromindonesia.id/ 2017/08/11/menengok-gunung-bromopesona-indonesia

Daftar Wilayah Metropolitan di Indonesia. Retrieved July 12, 2020, from https://id.wikipedia.org/wiki/Daftar_wilay ah_metropolitan_di_Indonesia Edward, J. 2019. Spring Summer 2019 Fashion Trends: The Trends to Shop Now. Retrieved April 10, 2019, from https://www.cosmopolitan.com/uk/fashio n/style/g23279363/spring-summer-2019fashion-trends/

Erliawati, T., Dewi I. A., \& Indra J. T. 2018. "Perancangan Busana Siap Pakai Deluxe Untuk Wanita Dengan Inspirasi Simbol dan Warna Suku Zulu Di Arfika". Jurnal ATRAT 6(3).

Jenis-Jenis Bordir. Retrieved September 7, 2016, from https://www.galerikonveksi51.com/blog/j enis-jenis-bordir/
Salsabila, A. 2017. "Pemanfaatan Teknik LipatIkat Celup untuk Menghasilkan Tekstur pada Kain Busana". e-Proceeding of Art \& Design 4(1).

Widodo, S.T. 2012. "Kriya Tekstil Tie-Dye (Ikat Celup): Sebuah Media Eksplorasi Estetis yang Populer". Jurnal Corak: Jurnal Seni Kriya 1(2). 